Supplement of Biogeosciences, 13, 5487-5497, 2016

http://www.biogeosciences.net/13/5487/2016/

doi:10.5194/bg-13-5487-2016-supplement

(C) Author(s) 2016. CC Attribution 3.0 License.

(c) (i)

Supplement of

\title{
Hydrologically transported dissolved organic carbon influences soil respiration in a tropical rainforest
}

Wen-Jun Zhou et al.

Correspondence to: Y.-P. Zhang (yipingzh@xtbg.ac.cn), L.-Q. Sha (shalq@xtbg.ac.cn)

The copyright of individual parts of the supplement might differ from the CC-BY 3.0 licence. 
Figure S1 Correlations between water and DOC concentration in the tropical rainforest at

22 Xishuangbanna, southwest China

23 A is the correlation between daily throughfall flux and DOC concentration

24

$\mathrm{B}$ is the correlation between daily litterleachate flux and DOC concentration

C is the correlation between daily soil water $(0-20 \mathrm{~cm})$ flux and DOC concentration

Figure S2 Correlation between soil temperature and soil water content of $\mathrm{CO}_{2}$ from eddy flux tower explained during soil respiration observation plot from Feb. 2008 to Jan. 2009 (a), soil respiration and temperature at $5 \mathrm{~cm}$ depth (b), and soil water content at $10 \mathrm{~cm}$ depth (c) in the tropical rainforest at Xishuangbanna, southwest China

Figure S3 Rainfall (A), throughfall (B), litter leachate (C), and surface soil $(0-20 \mathrm{~cm})$ water (D) dynamics in the tropical seasonal rainforest at Xishuangbanna, southwest China. 
35
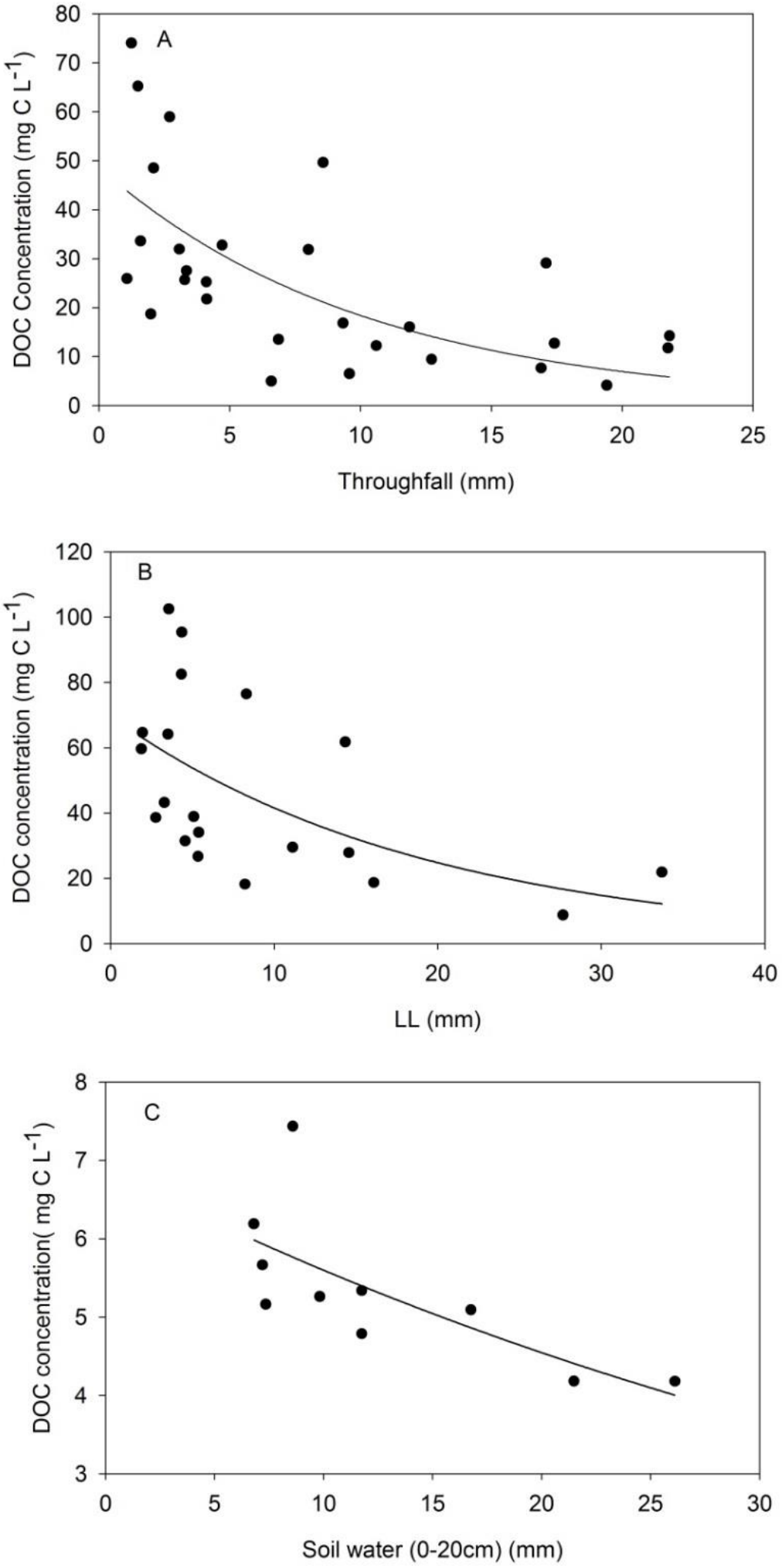
A

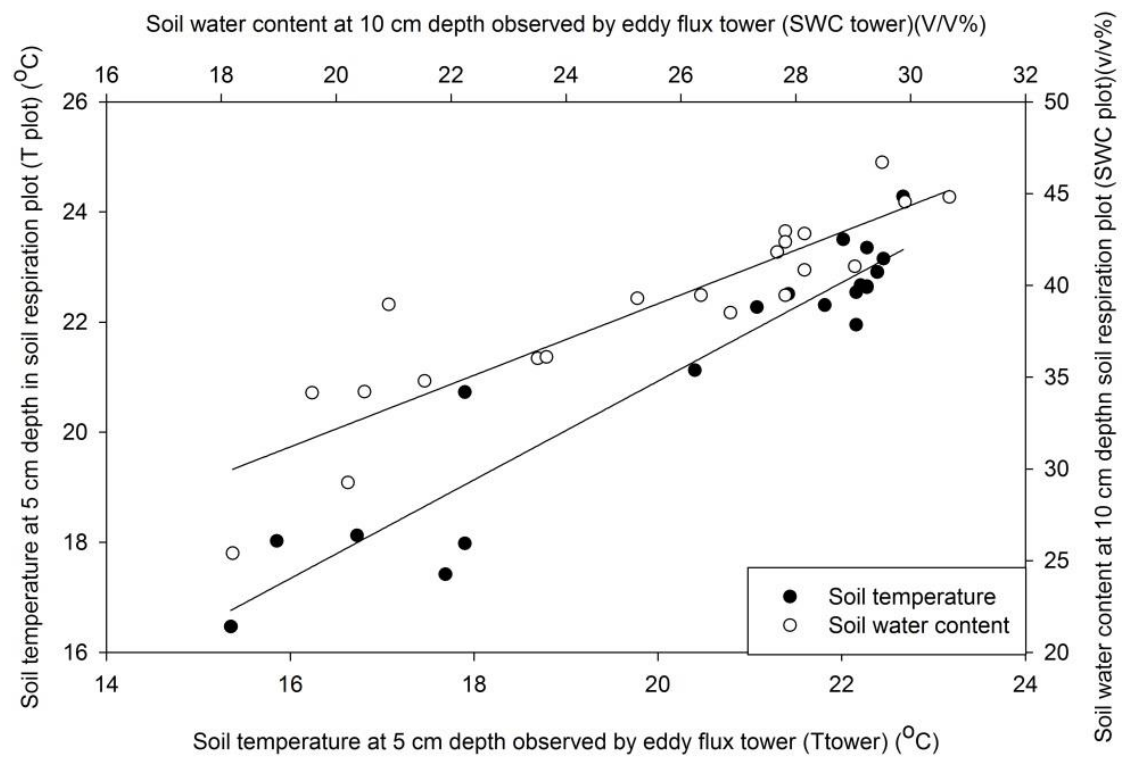

B

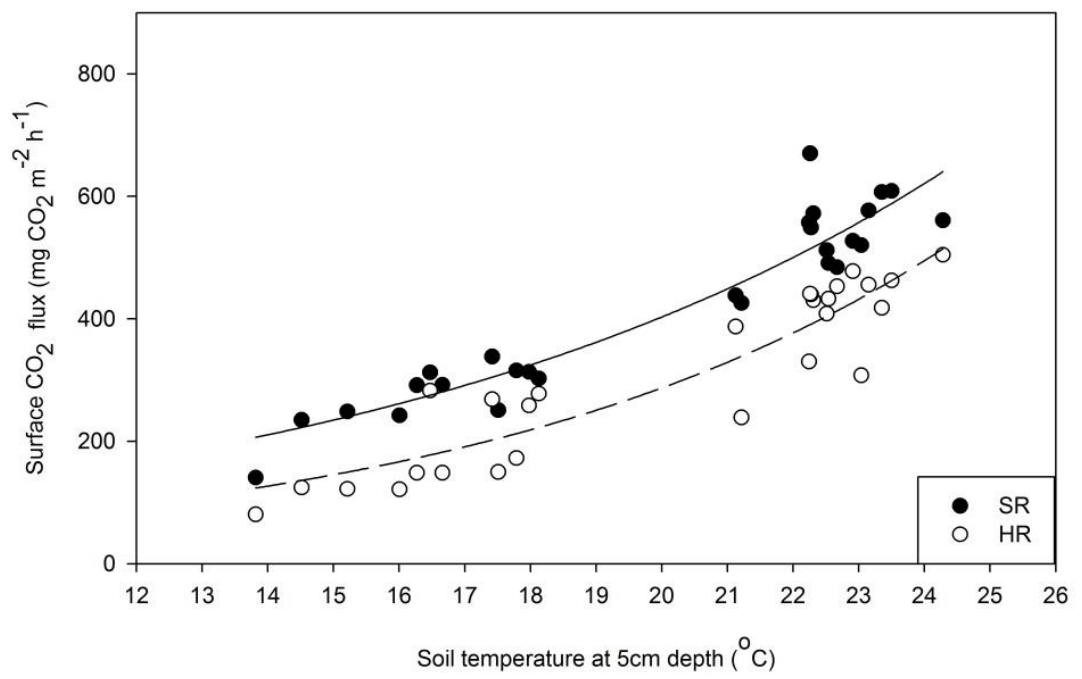

C

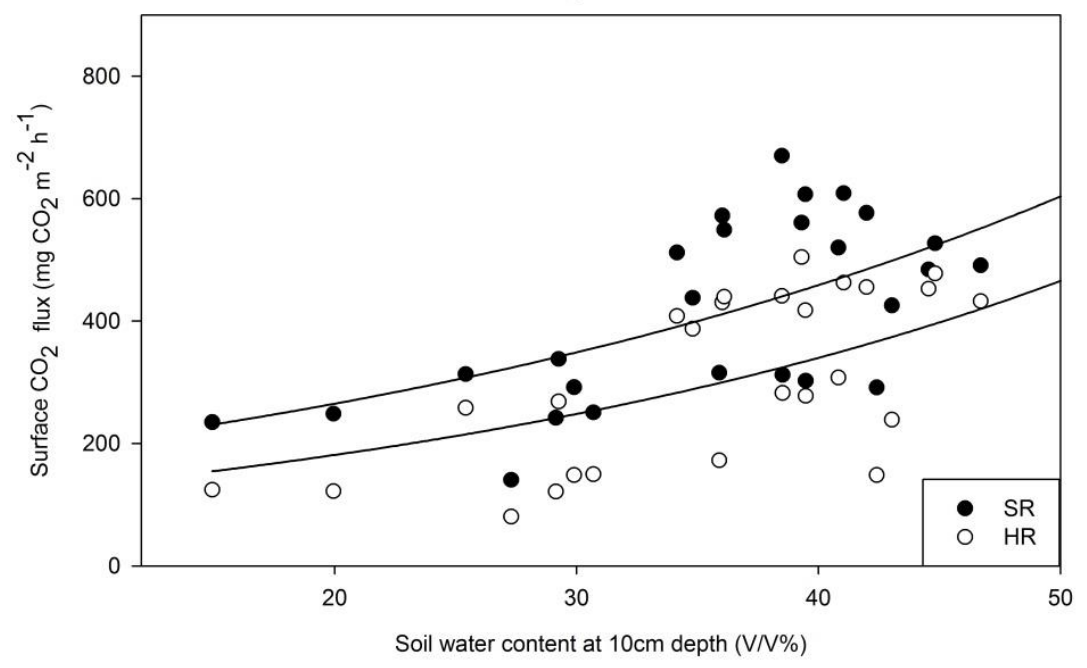




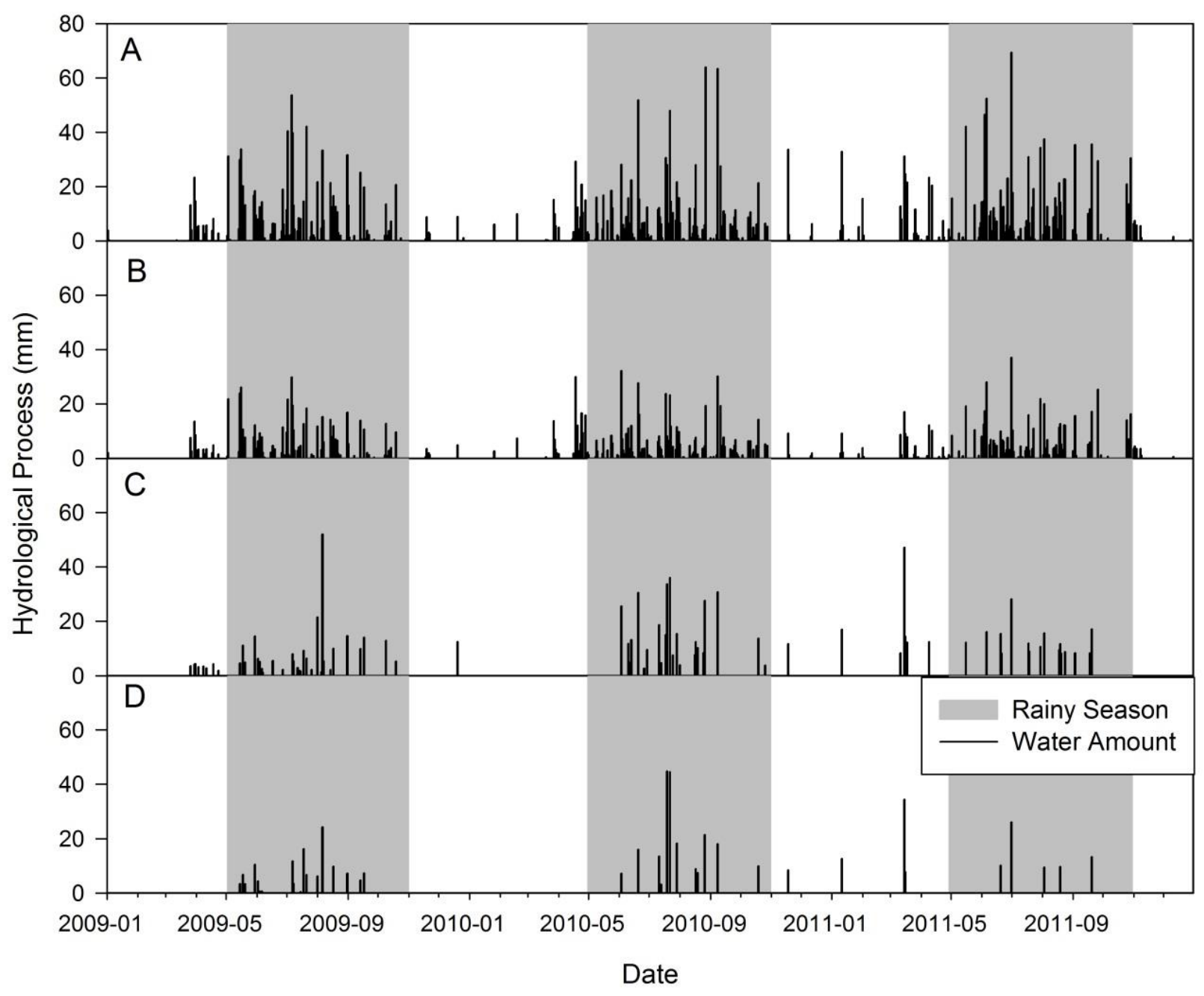

